\title{
AN INTRODUCTION TO CHEMICAL PRODUCT DESIGN
}

\author{
G. D. MOGGRIDGE and E. L. CUSSLER* \\ Department of Chemical Engineering, University of Cambridge, Cambridge, UK \\ *Department of Chemical Engineering and Materials Science, University of Minnesota, Minneapolis, USA
}

$\mathrm{T}$

his paper derives from an undergraduate course in chemical product design which we first taught in 1998/9 and are still in the process of developing. We are in the process of writing a text book to accompany such courses. We explain our approach to chemical product design and why the subject is important. The distinctive features of product design (particularly in contrast to process design, a more familiar topic for chemical engineers) are outlined in Section 1. The emphasis is on decisions which are required before chemical process design can be started. Our chemical product design course is a response to major changes in the chemical industry which have occurred in recent decades. These changes, described in Section 2 , involve a move in the industry away from the manufacture of commodity chemicals and towards speciality chemicals and other high added value products. The former is well served by traditional process design, the latter benefits also from product design.

Section 3 describes the product design procedure that we use. It is a simplification of procedures already used in business development and manufacturing engineering (see, for example, Ulrich and Eppinger ${ }^{1}$ ). Such a simplification clarifies the sequence of ideas involved and also forces us to consider in detail the technical questions implied in specific products. Our approach is aimed at those with training in engineering and chemistry, but may also be a beneficial challenge for those whose training is largely in business.

Keywords: product design; chemical products

\section{WHAT IS CHEMICAL PRODUCT DESIGN?}

We divide chemical products into three categories. First, there are new speciality chemicals which provide a specific benefit: pharmaceuticals are the obvious example. Second, there are products whose microstructure, rather than molecular structure, creates value, such as paint and ice cream (see for example Edwards ${ }^{2}$ ). The third category of chemical products are devices which effect chemical change: an example is the blood oxygenator used in open-heart surgery.

In most cases, chemical products like these have high added value but are made in small amounts in generic equipment. This is in stark contrast to commodity chemicals, which are produced in large volumes at small profit margins in dedicated equipment. Commodity chemical manufacture centres on the design of the chemical process. Chemical product design includes deciding what to make and how to make it.

Consider four chemically-based products: an amine for scrubbing acid gases, a pollution-preventing ink, an electrode separator for high power batteries, and a ventilator for a well insulated house. These four products may seem to have nothing in common. The amine is a single chemical species capable of selectively reacting with sulphur oxides. The ink is a chemical mixture, including a pigment and a polydisperse polymer resin. The electrode separator is a mechanical device which provides a safeguard against explosion if the battery accidentally shorts out by preventing the migration of chemical species. The ventilator provides fresh air, maintains humidity levels in the house and recovers the energy carefully secured by insulating the house in the first place.

What these products do have in common is the procedure by which they can be designed. In each case, we begin by specifying what is needed. Next, we think of ideas to meet this need. We then select the best of these ideas. Finally, we decide what form the product should take and how it can be manufactured.

Chemical product design is this entire procedure. Initially, when we are deciding what the product should do, we expect major input from marketing and research, as well as from engineering. By the end of the procedure, when we are focused on the manufacturing process, we anticipate a reduced role for marketing, but a major effort from engineering. However, we believe that the entire effort is best viewed as a whole, pushed through by integrated teams drawn from marketing, research and engineering.

The ink, the acid gas absorbant, the electrode separator and the home ventilator provide examples of chemical products. Their design is different from that of chemical processes. In process design we normally begin by knowing what the product is, and how much we want to make. Usually it is a commodity chemical of well defined purity; ethylene and terephthalic acid are good examples. This chemical will be sold into an already existing commodity market. The focus of process design is efficient manufacture. This is most often achieved by using a continuous process, requiring optimized and dedicated equipment, which is thoroughly energy integrated. This type of careful process design is essential in order to compete successfully 
in the commodity chemical business, where margins are small and direct competition fierce.

The type of chemical products which we are discussing are completely different. Their profit potential arises not so much from their efficient manufacture, more from their special functions. They are likely to be made in batch and using generic equipment; or may themselves be small pieces of equipment. Process efficiency may be less significant than time to reach the market place. Energy integration can be expected to be an issue of only secondary importance. Indeed, most of product design may occur before manufacture is even an issue.

We believe that chemical product design merits increased emphasis because of major changes which have occurred in the chemical industry. We do not argue that the chemical engineer's concern with process design should disappear but we do assert that the topics studied should reflect the nature of today's chemical industry, as outlined in the next section.

\section{WHY CHEMICAL PRODUCT DESIGN IS IMPORTANT}

The design of chemical products has increased in importance as a result of major changes which have occurred over recent years in the chemical industry. To understand these changes, we will review the industry's recent history, using the development of synthetic textile fibres as an example. We will see how employment patterns have been affected. Management style and structures have also altered to encourage a more integrated approach to product development, involving engineers at all stages of decision making.

\section{Changes in the Chemical Industry}

Between 1950 and 1970 the production of synthetic textile fibres increased dramatically, as shown in Table 1. During this period the production of natural fibres was about constant, but the production of synthetics grew $20 \%$ per year. This growth was comparable to that of the software industry today; Du Pont can be considered as the Microsoft of the 1950s. It was a golden age for chemicals.

From 1970 to 1990, synthetic textile fibre production grew by less than $5 \%$ per year, roughly the same as the growth rate of the world population. The industry stayed profitable by consolidating production into bigger plants, designed for greater efficiency in making a single product. The development of computer-optimized design was a consequence of this trend. Small producers were forced out, due to the economies of scale which could be achieved in

Table 1. Annual textile fibre production $\left(10^{6} \mathrm{lb}\right)$. From 1950 to 1970 , synthetic fibres grew about $20 \%$ per year. Since then, their growth has been only around $5 \%$ per year. (Source: P. Spitz ${ }^{3}$, US Department of Commerce).

\begin{tabular}{lrrr}
\hline & 1948 & 1969 & 1989 \\
\hline Cotton, wool & 4353 & 4285 & 4794 \\
Synthetics & 92 & 3480 & 8612 \\
\hline
\end{tabular}

large plant. For example, the number of companies making vinyl chloride shrank from twelve in 1964 to only six in $1972\left(\right.$ Spitz $\left.^{3}\right)$.

In the present decade, the industry has developed new strategies to stay profitable. These strategies often focus on restructuring, which has been three times more likely to affect engineers than the general population. Under the guise of 'restructuring', 'downsizing', 'rightsizing', or 'rationalization', this has meant many mid-career engineers suddenly looking for new jobs. The Engineering Workforce Commission believes that today's engineers will average seven different jobs per career, a dramatic change from two per career which could be expected in the recent past. Middle management is no longer the safe haven it once was. While starting salaries for chemical engineers remain high, the envy of other technical professions, the growth of these salaries has not outpaced that of average salaries in thirty years. Most recently, the chemical industry has become enchanted with the life sciences, often called 'biotechnology', most successfully represented by applied agronomy, i.e. by genetically modified seeds.

Having exhausted optimization and restructuring as ways to stay profitable, chemical companies now have three remaining options. First, they can leave the chemical business. This option seems reasonable to a surprising number, including many petrochemical businesses. Second, chemical companies can focus exclusively on commodities. This seems a preferred strategy for some private companies, who may be better able to handle the ebb and flow of a commodity business. It inevitably requires a ruthless minimization of research and dedication to in-house efficiency.

The third strategy open to chemical companies is to concentrate on speciality chemicals. Such chemicals, produced in much smaller volumes than is usual for commodities, typically have much higher added value. This higher added value means that more research and higher profits are possible. Unsurprisingly, many chemical companies are turning their focus to speciality chemicals or other high added value products.

Interestingly, this new emphasis has not dramatically changed the skills that companies demand from chemical engineers, but it has changed the jobs that they do. We would maintain that the skills base required by chemical engineers is diverse and remains remarkably unaltered by the changing nature of the industry. Heat and mass balances, thermodynamics and transport processes are as relevant for designing high added value products as for process optimization.

Although changes in the chemical industry may not have changed the skills needed, the focus of chemical companies on specialties has had a major impact on the jobs which chemical engineers are expected to do. To illustrate this, we consider the jobs taken by recent graduates with those taken by graduates twenty five years ago. Our data are fragmentary, taken from records of graduates from Cambridge and Minnesota Universities, and probably biased towards large corporations, about which our university placement offices have better records.

The available data indicate major changes. In 1975, three quarters of chemical engineering graduates went to work in the commodity chemicals business. The rest were split between work on products, either design or development, 
and work in other areas such as consulting or financial services.

The distribution of jobs is now completely different. The largest group of chemical engineering graduates, in Minnesota's case more than half, now work in productoriented companies. This includes graduates who work on materials, pharmaceuticals, coatings, adhesives, and speciality chemicals. The number who enter employment in commodity chemicals has dropped to less than a quarter of new graduates. The number starting work in consulting has risen dramatically, as commodity chemical businesses outsource many of the functions which they used to do in house. For example, in one case, a commodity chemical company reduced its process engineering group from 1500 to fewer than 50 persons. This is not a business cycle; this represents a change in the way in which companies expect to do business and is why the number of people involved in consulting has risen.

The emergence of product development as a focus for chemical engineers implies changes in what chemical engineers do. This in turn must imply changes in the appropriate undergraduate curriculum. We have argued that the knowledge base of traditional chemical engineering remains highly relevant. We suggest that the appropriate place for changes is in the teaching of design.

\section{Changes in Responsibility}

We have suggested that a new approach to teaching design to undergraduate chemical engineers is necessary because our graduates are now moving into a more product-oriented type of company than they were twenty years ago.

A second reason that chemical product design should be taught follows from a major change in corporate organization. The organization of chemical product development has traditionally been functional. Marketing decided what to make; research discovered how to make it; and engineering developed the chemical process. Now, product teams drawn from marketing, research and engineering work together to develop better products faster. Our new graduates need to be ready for these broader teams which decide both what to make and how to make it. In the past, we chemical engineers could limit our thinking to reaction engineering and unit operations, waiting for the marketing division to tell us what chemicals needed to be made, and in what amounts. Such intellectual isolation is no longer possible. We must expect to be involved in teams of marketers, synthetic chemists and operations engineers in the joint effort of product design and to participate in the whole enterprise from conception to manufacture.

\section{THE CHEMICAL PRODUCT DESIGN PROCEDURE}

Product design is a major topic in subjects such as sales and marketing, and in other technical professions like mechanical engineering (Cooper ${ }^{4}$, Graedel and Allenby ${ }^{5}$, Gregory $^{6,7}$, Kao and Wiersema ${ }^{8}$, McGrath ${ }^{9}$, McMillan ${ }^{10}$, Pahl and Beitz ${ }^{11}$, Rosenau et al. ${ }^{12}$, Whitfield ${ }^{13}$ ). Not surprisingly, the schemes for the design procedure vary widely. Many are complex, especially with respect to the role of management (Blessing ${ }^{14}$, Grabowski ${ }^{15}$, Rude and
Grein ${ }^{16}$ ). Often they have features specific to the particular sub-discipline that they represent.

In developing our material, we wanted our teaching to be independent of case studies of particular products. Case studies can have considerable value: the design of a high performance lithium battery can help students understand product design just as the design of a styrene plant can teach students about process design. However, students can learn more effectively if their understanding is in the context of a broader philosophy, a template for organizing their thinking.

The product design procedure we propose is a simplification and generalization of schemes used in mechanical engineering ${ }^{1}$. We have chosen a four step design scheme, centred around the concepts of 'needs', 'ideas', 'selection', and 'manufacture'. Similar schemes are said to be used in such diverse companies as Du Pont, Motorola, and W. L. Gore.

1. Needs. What needs should the product fill?

2. Ideas. What different products could fill this need?

3. Selection. Which ideas are the most promising?

4. Manufacture. How can we make the product and test it critically?

In defining 'needs', we must define who our customers are, a marketing function, and convert their requirements into quantitative specifications, an engineering task. In generating 'ideas' to satisfy these needs, it is helpful to start from the industrial consensus that we will need up to one hundred ideas to get one successful product. In the 'selection' of the best ideas for development, we use both qualitative matrix screening techniques, another business idea, and order-of-magnitude calculations, not much more detailed than typical homework problems, but firmly rooted in traditional engineering teaching. In 'manufacture', we proceed roughly along the lines of conventional process design, but often using batch reactors and generic pilot plant scale separations equipment.

These four steps are the key to the organization of our approach to chemical product design. Customers' needs include deciding on a standard for comparison-a benchmark-and converting qualitatively expressed wishes into quantitative and scientific specifications. The benchmark chosen may be an existing product or an ideal. It must be as well defined as possible so that specifications are definitive.

The generation of ideas which might meet these needs is the next step in product design. Normally, we will search for a large number of such ideas using all reasonable means. This search may include brainstorming by individuals and teams, literature and patent searches in similar or related areas and synthesizing tangent compounds, using methods such as combinatorial chemistry. Once the numerous ideas are identified, they must be screened, using both objective and subjective judgements.

At this point, we should have reduced the large number of fragmentary ideas for products down to a short list of the most promising candidates. This reduction might be about a factor of twenty: if we start with a hundred ideas, we should have about five survivors. We must now select the best one or two for detailed design and development. If the characteristics of each of the remaining ideas were directly comparable, this would be easy. They normally 
are not. For example, we might be sure that one idea will work well but be expensive; and a competing idea could be cheap but may not work. Deciding between these ideas includes the assessment of risk.

Finally, we must build and test prototypes of possible products, and estimate the costs involved in production. The focus of these efforts is different from that expected for commodity chemicals, where we expect dedicated, optimized equipment which operates continuously and the product is usually well known and understood (for example in terms of toxicity, flammability, storage lifetime). For small volume, high value products generic equipment, run in batch for a series of speciality products is usually more appropriate. Considerable effort must be expected in testing the product for safety, reliability, etc.; this is particularly true in the pharmaceutical industry where mistakes are catastrophic.

This type of work is different to traditional chemical engineering - and it is exciting.

\section{Limitations of This Procedure}

The four-step procedure outlined above is controversial. The controversies cluster around three issues: that the procedure is not general, that management and not technology is the key to successful product development, and that product design is already part of chemical process design. Each controversy merits discussion.

The four-step procedure is obviously a major simplification. Many business texts argue that such a procedure is universally applicable for any product in any industry. These texts are usually written by business consultants eager to make money by applying their own procedures to specific problems. At the same time, many professional product developers argue that this or any procedure does not represent the peculiarities of their own industry, that only those with particular interests can hope to be effective. To some extent this view must be correct-expertise in a particular area will be required and unique problems will exist in each field of product development. In a way, however, these product developers are like those who have denied that correlations of heat transfer could be used for food products because they were based on measurements for petrochemicals. Even though differences exist, it is possible to find general principles common even to very diverse fields.

The four-step procedure we have suggested is unquestionably an approximation. Certain techniques introduced in particular steps can have value at other steps. For example, risk management may have value in screening product ideas. Several iterations between stages may also be necessary-considerations of how to manufacture the product might necessitate a rethink of the selection phase. Nonetheless, we must start somewhere, and the current procedure has been for us a sound and creative beginning. We suggest trying it; any necessary modifications quickly become obvious in specific cases.

An irritating characteristic of most business books on product design is their emphasis on the central role of management. The implication is that technology is always available if only the managers do their job properly (or at least do what the consultants say). These books on product design recognize no inconvenient constraints like the second law of thermodynamics or the meaning of Avagadro's number.

We believe that understanding technology is central to the design process for chemically-based products. Product design brings to mind a Sidney Harris cartoon showing a few managers and an engineer standing in front of a flip chart. Though the flip chart is covered with equations, pie charts, and organization charts, the engineer is pointing to one small box, which says: 'then a miracle occurs.'

The engineer remarks: 'I'm having trouble with this part.'

Reading books on the management of product design, we can feel all too much like the engineer in that cartoon. In our approach, we ensure that technology is carefully considered throughout the design procedure. This is what makes chemical product design distinct from related subjects in business studies or mechanical engineering and is why it is an appropriate concern for chemical engineers.

The third objection is the assertion that the subject is already covered as part of the existing study of process design. This serious assertion is most easily tested by comparing our template for product design with the intellectual hierarchy usually suggested for process design. One successful and powerful hierarchy, suggested by J. M. Douglas ${ }^{19}$, is summarized on the left side of Table 2. After deciding whether a process is best performed in batch or continuously, one then moves on to producing flow sheets, which are almost always continuous. The initial flow sheets centre on the stoichiometry-mass and heat balances. The next level of the hierarchy, which adds the recycles, often involves a discussion of the chemical reactions. Once these are established, one moves on to the separation trains and finally to the heat integration. All of this makes for a good course.

If we want to emphasize product design, we need to go beyond this hierarchy. We cannot simply substitute a product for drug delivery for the existing process and carry out the same kind of procedure. For comparison, the fourstep hierarchy suggested earlier is shown on the right side of Table 2. After first identifying a corporate need, ideas are generated to fill this need. One then decides between these alternatives and finally a prototype is made and a method of manufacture identified. The manufacturing step includes all of the process design hierarchy, although the level of detail required at this stage in a typical product design can be expected to be much lower than that needed in process design-because the scale of production is usually much smaller and because profit depends more on added value than manufacturing efficiency.

Thus the important steps of product design anticipate those of process design. Product design implies a focus on the initial decisions around the form of the product and implicitly de-emphasizes its manufacture. This shifts our

Table 2. Process design vs. product design. All of process design is contained in the last step of product design.

\begin{tabular}{ll}
\hline Process Design & \multicolumn{1}{c}{ Product Design } \\
\hline 1. Batch vs. Continuous Process & 1. Identify Customer Needs \\
2. Inputs and Outputs & 2. Generate Ideas to Meet Needs \\
3. Reactors and Recycles & 3. Select among Ideas \\
4. Separations and Heat Integration & 4. Manufacture
\end{tabular}


efforts away from the common engineering calculations that have been our bread and butter and requires consideration of subjects that are traditionally left to those directly concerned with business.

\section{CONCLUSIONS}

Chemical product design is the procedure by which customer needs are identified and translated into commercial products. This procedure, which precedes process design, is especially valuable for speciality chemicals. Such specialties are an important focus of the present-day chemical industry, which is evolving beyond the commodities that have been the emphasis in recent decades. We argue that changes in the chemical industry make a greater emphasis on product design in chemical engineering education imperative.

We further argue that it is useful to provide an intellectual framework in teaching chemical product design, although this template for design is necessarily a simplification and will need to be adapted to particular cases. We organize the product design procedure as four sequential steps. The first is the identification of customer needs and the translation of the needs into product specifications. The second step involves generating and winnowing ideas to fill these needs. In the third step the best ideas are chosen for commercial development. The last step requires product prototyping, decisions on manufacturing route and estimation of economic boundaries. The result is a template for chemical product design.

Our course has been sufficiently successful that it is now part of the required undergraduate curriculum at the University of Minnesota and at Cambridge University and we are producing an accompanying text book. We recommend that the product design material be taught after the material on process design, because we feel that students benefit from learning more quantitative process synthesis before trying to make qualitative decisions concerning products. We suggest that a chemical product design course should be about one third lectures and two thirds tutorials or design projects. While the lectures should be spread throughout the semester, they should be more frequent at the beginning of the course. Finally, the material can be used for a short course containing lectures alone, though we believe that this may be less effective for inexperienced students of uneven ability.

\section{APPENDIX-A Case Study Designing a Pollution Preventing Ink}

A company prints personal cheques with a lithographic ink containing carcinogenic solvent methylene chloride $\left(\mathrm{CH}_{2} \mathrm{Cl}_{2}\right)$. Workers at this company also clean the presses by wetting a shop rag with the same solvent, and scrubbing down the press. This procedure works well. The trouble is that much of the methylene chloride evaporates and so risks damage to worker health and censure from the environmental authorities. Also, the soiled rags have recently been reclassified as a hazardous waste, so that the cost of their disposal almost equals the cost of buying the solvent in the first place.

The company clearly needs to use a different ink; one which has less negative environmental impact. Below is a schematic of the design process, based on the template described above, used to solve this problem. We hope that this example illustrates both that applying a design template can be a helpful and productive technique and that the template will need to be adapted to the specific problem at hand. In this case the identification of needs is pretty straightforward as is manufacture (it is already known how to make the ink); emphasis is therefore on the ideas and selection stages. Other problems will require emphasis elsewhere. It is crucial that the design procedure is seen as a flexible tool, rather than a straightjacket for creativity.

\section{Needs}

Needs will be identified by interviewing the company's management, workers, environmental consultants and health and safety administrators. This will give a picture both of what is required from a perspective within the company and the external pressures which exist. It may also be instructive to interview cheque users; this may lead to some innovative thinking in terms of a completely new approach to cheque use. The resulting needs statement might go as follows:

1. keep printing cheques, without loss of quality

2. reduce emissions of chlorinated solvents by at least $95 \%$

3 . eliminate exposure of workers to carcinogens.

We can obviously use the existing process as our benchmark.

\section{Ideas}

Idea generation will involve consultation with 'expert' consultants, literature and patent searches, competitor analysis and most importantly brainstorming within the company. A long list of ideas will result. Many will be incomplete, there will be plenty of duplication and some will be plain folly. In most cases it will not at this stage be entirely clear how each idea will work; for example an idea may be to use a different (less polluting) solvent-but we don't yet know which one. None of this matters. At this stage we are interested only in generating as many ideas as possible, sparking as much creativity and lateral thinking as we can. It is easy to prune the ideas in subsequent stages, but missing a good solution might be disastrous.

Having generated a list of ideas, we want to prune and sort them, removing the plain ridiculous and duplication. The remaining ideas might be broken into four groups, as shown below.

\section{Sorted Ideas for a Pollution Preventing Ink}

I. Improve Current Printing
A. Change Press
1. Isolate Press
2. Use Laser Printer
3. Use Photocopying
B. Change Cleaning
1. Less Often
2. Solvent-Free Spray, Steam, Air

II. Use a New Solvent

A. Change $\mathrm{CH}_{2} \mathrm{Cl}_{2}$ Operation

1. Recycle

(i) Extract

(ii) Spin Dry 
2. Burn

3. Freeze

B. Replace $\mathrm{CH}_{2} \mathrm{Cl}_{2}$

1. Non-volatile solvent

2. Oil as Solvent

3. Solvent Mixtures

III. Solvent-Free Ink Chemistry

A. Electrostatic Ink

B. 'Solvent which Dissolves Ink'

\section{Don't Use Cheques}

The first group in of ideas involves changes in the printing presses. Because the company does not want to make the enormous capital investment involved in changing the presses, this group is deferred until other alternatives are explored.

The second group involves either containing the solvent or using a different solvent. These ideas are the easiest to implement, and hence the most tempting for further development. The third group of ideas implies the invention of a new ink, a more major effort than the substitution of a new solvent, but an attractive solution.

The final idea, 'Don't use Cheques', may initially seem foolish; but consider the explosion in electronic money transfers. The company may decide that electronic data processing which replaces hand-written cheques is like automobiles which have replaced horse-drawn buggies. If so, then printing cheques may be like making buggy whips. Thus this fourth idea should be carefully considered in the idea screening which is to follow.

A quick screening of the ideas might lead us to choose IIA1, IIB1, IIIB and IV as the most promising ideas to be taken forward for further consideration. We are not at this stage making detailed calculations about how each idea will work. We are simply comparing each idea with our specified needs and choosing those which look most hopeful. We can always come back at a later stage and look at some more of the ideas, if those we have taken forward all seem inadequate in some way. At this point we need to cut down the number of ideas so that it is practical to analyse them in more detail.

\section{Selection}

It is now necessary to put flesh on the bones of each of the ideas we have taken forward from the ideas phase, so that we can make a rational decision as to which will work best. All the ideas we have taken forward to this point should seem attractive-each must hold out a good prospect of solving our problem and so detailed analysis will be necessary to choose between them.

For the purposes of this example, a lithographic ink can be idealized as containing only four components: a pigment, an oil, a resin, and a solvent. The pigment, frequently colloidal carbon, is important to the ink, but not a key in pollution. The oil is a mixture of natural products like castor and linseed oils. It typically contains fatty acids with multiple double bonds, like linoleic acid and linolenic acid. These double bonds crosslink in the presence of oxygen, making the ink permanent. The resin is a low molecular weight, highly polydisperse condensation polymer, made for this purpose. The solvent, frequently methylene chloride $\left(\mathrm{CH}_{2} \mathrm{Cl}_{2}\right)$ is used in combination with the resin to adjust the ink's rheology in order to give good printing.
It is fairly clear how recycling the ink (IIA1) will workit is a straightforward piece of conventional chemical engineering. It is a good idea and will work well, but probably will require considerable investment to implement it. We would prefer to implement a cheaper solution if possible. The idea of not using cheques (IV) is interesting, but will take a long time to materialize and is to a great extent beyond the company's control. We need a fast solution, as the environment agency are threatening to shut our operation down. We should keep looking at this idea and may ultimately decide to get out of the cheque printing business as a consequence, but we need a more immediate solution too.

We are therefore most interested in either using a new solvent or in developing a solvent-free ink. We need details of how these ideas will work, so that we can select the best one, or reject both in favour of solvent recycling.

To find a new solvent, we can make use of the theory of the thermodynamics of mixtures, in particular Hildebrand solubility parameters. Chemicals with similar solubility parameters dissolve well in each other. We know that methylene chloride is a good solvent for our ink. If we can find an alternative chemical with a similar solubility parameter, then it too is likely to be a good solvent. Methylene chloride has a solubility parameter of $9.8\left(\mathrm{cal} / \mathrm{cm}^{3}\right)^{1 / 2}$. Inexpensive solvents with similar solubility parameters are benzene, toluene, and napthalene. These are three possible choices as alternative solvents. All are carcinogens, though perhaps less dangerous than methylene chloride. Benzene is excessively carcinogenic, and napthalene is solid at the temperatures normally used for printing. Thus we choose toluene as a substitute for methylene. This is a conservative choice: the toluene is still toxic and will still generate emissions, but the modified ink should still work well. This idea is unlikely to be a long term solutiontoluene is eventually likely to be banned too, but it might be a good stop-gap measure whilst we look for an alternative solution.

To explore developing a solvent-free ink, we begin by asking what parts of the ink we can change. We could alter the pigment's surface chemistry, but this would probably have little effect. We cannot change the natural oil much. Our best chance is the resin.

Changes in the resin could provide the desired product. First, we can synthesize the resin so that it has a lower average molecular weight and a broader molecular weight distribution. With some experimental work, we may get a resin whose rheology is such that distribution with a solvent is unnecessary. This would eliminate vapour emissions during printing and hence one of the sources of pollution.

We might also consider making the ink water washable. During printing, the ink must be hydrophobic. To also be water washable, we need some sort of chemical trigger, which we activate after printing is over, to clean the presses. One such trigger would depend on a resin with pendant carboxylic groups $(-\mathrm{COOH})$. Such a resin would normally be hydrophobic. However, if the ink were washed not with water but with dilute aqueous base, these groups would ionize and the resin would become considerably more hydrophilic. If there were enough pendant carboxyl groups, the ink could become its own emulsifying agent, and be washed off the presses with aqueous base. A resin 
with pendant carboxylic acid groups is a riskier choice, but offers hope of a permanent solution.

The selection stage leads us to carry forward the ideas of solvent substituion (as a temporary measure to keep us printing) and changing the resin chemistry as a longer term solution. We might also want to keep the idea of not printing cheques at all on the back-burner in terms of company strategy.

\section{Manufacture}

We have now identified our solution(s) - we have to put them into operation. This involves a full product specification and details of how manufacture will occur. In this example this stage is pretty straightforward; after all we already know how to manufacture the ink. It is particularly simple for the solvent substitution. All that is required is some quick experiments to confirm that toluene is an adequate substitute and to determine how much should be used in the ink formulation to ensure good rheology.

There is considerably more work to be done in changing the resin chemistry. This is a more innovative idea and as such much more needs to be done in order to get the idea to work. We need to identify a suitable resin formulation, test its performance both for printing and washing and then decide on a manufacturing route. Whilst this may take a long time and be a labour intensive and creative procedure, the path is clear and lies within the bounds of conventional process engineering. We now know what we want to make, we just need to decide how to make it. This is where chemical product design merges into process engineering.

\section{REFERENCES}

1. Ulrich, K. T. and Eppinger, S. D., Product Design and Development, (McGraw-Hill, New York) ISBN 0-07-065811-0.

2. Edwards, M. F., 1998, The importance of chemical engineering in delivering products with controlled microstructure to customers, IChemE, North Western Branch Papers, No. 9.

3. Spitz, P., 1988, Petrochemicals: the Rise of an Industry, (Wiley, New York).

4. Cooper, R. G., Winning at New Products, Accelerating the Process from Idea to Launch, Second Edition, (Addison-Wesley Publishing Company) ISBN 0-201-56381-9.

5. Graedel, T. E. and Allenby, B. R., Design for Environment, (Prentice Hall, Inc) ISBN 0-13-531682-0.

6. Gregory, S. A. (Ed.), 1966, The Design Method, (Butterworths).

7. Gregory, S. A. (Ed.), 1972, Creativity and Innovation in Engineering, (Butterworth).

8. Kao, J. and Wiersema, F., Breakthrough Thinking at 3M, DuPont, GE, Pfizer, and Rubbermaid Innovation, (Harper Collins) ISBN 0-88730771-X.

9. McGrath, M. E., Setting the Pace in Product Development, A Guide to Product and Cycle-Time Excellence, Revised edition, (ButterworthHeinemann) ISBN 0-7506-9789-X product.

10. McMillan, J., Games, Strategies, and Managers, How managers can use game theory to make better business decisions, (Oxford University Press) ISBN 0-19-507403-3.

11. Pahl, G. and Beitz, W., Engineering Design, A Systematic Approach, Second edition, (Springer) ISBN 3-540-19917-9.

12. Rosenau, Jr. M. D., Griffin, A., Catellion, G. A. and Anschuetz, N. F., The PDMA Handbook of New Product Development, (John Wiley \& Sons, Inc) ISBN 0-471-14189-5.

13. Whitfield, P. R., 1975, Design and Creativity, (Penguin Books Ltd).

14. Blessing, L. T. M., A process-based approach to computer-supported engineering design, PhD Thesis, (University of Twente) ISBN 0 952350408 .

15. Grabowski, H., Rude, S. and Grein, G. (Eds.), Universal Design Theory, (Springer Verlag) ISBN 3-8265-4265-7.

16. Rude and Grein.

17. Douglas, J. M., 1988, Conceptual Design of Chemical Processes, (McGraw-Hill, New York).

\section{ADDRESS}

Correspondence concerning this paper should be addressed to Dr G. D. Moggridge, Department of Chemical Engineering, University of Cambridge, Pembroke Street, Cambridge CB2 3RA, UK. (E-mail: gdm14@cus.cam.ac.uk).

The manuscript was received 17 September 1999 and accepted for publication after revision 19 November 1999. 